\title{
Single Port Laparoscopic Surgery- Are there Limitations of Minimal Invasive Surgery? Definition of an Opinion
}

\author{
Matthias Kapischke* and Alexandra Pries \\ Department of Surgery, Staedtisches Klinikum Guetersloh, Gemany
}

Received: 阱July13, 2018; Published: 跚 July 19, 2018

*Corresponding author: Matthias Kapischke, Department of Surgery, Staedtisches Klinikum Guetersloh, Reckenberger Strasse 19, 33332 Guetersloh, Germany, Tel: +49 5241 8323202; Fax: +49 5241 832308; Email: mkapischke@web.de

\begin{abstract}
There are a significant number of reports about single port operations available in the scientific publications. The advantage of lower access trauma compared to conventional laparoscopy is frequently propagandized; nevertheless, taking factors like Health-related Quality of Life (HrQoL), shorter hospital stay or improved cosmesis into consideration it becomes difficult to find confirmation of the above in the existing studies. There remains an assumed equality to the standard procedure in particular operated organ systems with considerably higher costs when using commercial available ports and specific angulating instruments. It still remains unclear which patient population is most suitable for this technique. Currently single port technique does not have evident advantages compared to conventional laparoscopic surgery. It is to be hoped that current and future clinical trials provide insight and clarity.
\end{abstract}

\section{Introduction}

Over the last few decades minimally invasive techniques revolutionised surgery: severe reduction of access trauma, accelerated remobilisation and a significantly shortened hospital stay for the patients, just to mention a few advantages [1]. Technical innovation appeared to have no limitations. Ensuring from standard surgeries like cholecystectomy and appendectomy the minimal invasive spectre was widened from midsize surgeries to the most complex operations like pancreatic, major hepatic und esophageal resections. It is without any question that nowadays no surgeon wants to miss minimally invasive surgery in his surgical portfolio. Retrospective studies followed feasibility analyses; however, the number of double-blinded randomised clinical trials (RCT) comparing minimal invasive procedures with the respective open surgery is rather limited.

In the end had to realise that the advantages of minimal invasive surgery are limited to the direct post-operative course. With longer distance to the primary surgery the patient apprehended benefits of the laparoscopic technique especially HrQoL reduce more and more and there remain in the best case very soft and subjective (mostly cosmetic) advantages [2-4]. However, the development towards even more minimal invasive procedures proceeded; there followed single incision laparoscopic surgery (SILS) or single port surgery (SPS) as procedures to further reduce access trauma. Considering evidence-based medicine: what remains currently of the postulated advantages of those "more minimal invasive" techniques?

\section{Acronyms of the Reduced Port Site Surgery}

For the one port techniques various names are nowadays established. SILS = single incision laparoscopic surgery, SPA = single port access surgery, OPUS = one port umbilical surgery, LESS = Laparoendoscopic single site surgery, $\mathrm{S}_{3}=$ single site surgery, SAS = Single access surgery, SIMPLE = single incision multiple port laparoendoscopic surgery, SPS = single port surgery, SPL = Single port laparoscopy, SAVES = single access video endoscopic surgery, TUES = Transumbilical endoscopic surgery [5]. As base of the procedure remains that the number of skin incisions is reduced to one. It is only far to mention that there are various tricks to compensate the loss of additional ports with additional transcutaneous holding threats or mini instruments.

\section{History of a Development}

As first single portoperation should be defined an appendectomy described by Pelosi [6]. Navarra published a first case study for cholecytectomy with 30 patients in 1997 [7]. Two years later Piskun reported about 10 patients for cholecystectomy too [8]. All reports showed self-made ports with standard instruments adopted from conventional laparoscopic surgery. Since then a very intensive development of various industrially produced and self-made ports as well as miscellaneous specified instruments started.

\section{Relevant Benefit of Reduction of Access Trauma}

The conventional laparoscopic surgery has significantly reduced the operative access trauma; given it is in the interest of the patient it is reasonable to continue working on further reduction. However, there remains the question if the necessary effort and the danger if the measured improved parameters are pure surrogate parameters without any clinical relevance. Relevant factors are

i. surgical quality equivalence to the standard procedure, 
ii. reduced hospital stay,

iii. costs versus (any) as subjective and measureable improvement regarding HrQoL of the patients.

Surgical Equivalence: One has to state in a very austere fashion that 20 years after the first published single port operation no really good validated RCTs to compare SILS with conventional laparoscopic surgery are available; this refers to each operated organ system. Most data derive out of small groups compared (often) to historical reference groups. Here we have to postulate a significant selection bias of the patients [9]. These studies all satisfy "non-inferiority criteria". Severe complications for the SILS technique are described like injuries of the common bile duct during cholecystectomy [10], as well as frequent umbilical seroma and higher incidence of umbilical or port site hernias [10-13]. With a focus on the small sample size one has to question the value of missing significances in the differences even in meta analyses [14]. It remains the danger of underestimating the risks [15-17].

Postoperative Pain: Frequently the advantage of SILS regarding the post-operative pain relief is emphasized [18]. Even here remain existing data are in homogeneous, not double blinded and very selective [19]. At the best is the benefit in pain scores for SILS patients during the first 24 hours. In addition to it the available data are not significant $[20,21]$. A current appendectomy study had to be stopped since the SILS group presented with significantly higher pain compared to the control group and showed a higher consumption of analgesics [22].

Hospital Stay: In smaller studies there is a trend towards a shortened hospital stay in the SILS group. Given there was not blinding in these studies the possibility of a selection bias may be classified as high. In general, most available studies do not present a significant difference in hospital stay [20].

Recovery/Return to daily activity/ HrQoL/Cosmesis: Already from the comparison of laparoscopic surgery with the open operation is known that advantages of the laparoscopic procedure reduce dependent from the longer time interval to the primary operation [2,3]. A similar phenomenon can be seen if conventional laparoscopic surgery is compared to SILS. The question if patients are able to transform their (possible) better cosmetic results into HrQoL remains unanswered; just like the question if minimally less pain in an improved return to daily activity. It appears as if there is a minimal advantage of SILS regarding the return to daily activity [23]. Taken together the study results regarding these problems are very heterogeneous a clear advantage of the SILS technique regarding HrQoL cannot be confirmed [24]. It should be made the point that the in single studies as high considered cosmetic advantage of SILS vanishes in the meta analyses [23, 25-27].

Costs: Available cost evaluations are hardly comparable often the calculation is not transparent [28]. Considering the costs for the port and most likely investing in angulating instruments one can postulate the sole surgery costs are higher than in conventional laparoscopic surgery [25]. For sure may find one or the other study applying self-made single ports in order to optimise costs with this approach [29]; but what about validity of this procedure in times of high technology and product certification of conformity if surgeons produce their instruments themselves, given that the time requiring for factoring this self-made port is not considered in the cost evaluations. Quite a number of evaluations show that cost advantages of SLS is achieved by a shortened hospital stay [30]. Again remains the obstacle of a selection bias due to the lack of blinding without a medical reason for the longer hospital stay of the conventional laparoscopically operated group.

\section{Discussion}

It is without any question that the improvement of laparoscopic techniques will further advance. Nevertheless it remains questionable if the various forms of SILS operations will have a future. The fast increasing number of publications (Figure 1) does not reflect the meaning of this procedure in daily surgical practice. Segments of technical developments or postoperative management will be applied for other surgical procedures and are quite versatile. SILS port applied in transanal surgery may serve as a very good example for this development [31,32]. Refinement of surgical techniques is a fascinating world; with all the considerations in min it is still a requirement that surgical technique does not only develop for itself but a detectable benefit for the patients is achieved and cost-benefit-ratio remains structured. Certainly, there are studies which address each and every of the above aspects in a more advantageous fashion and therefore provide a further favourable point of view for SILS. Still there is the situation that there is only thin evidence for the objectifiable advantages of the SILS technique $[23,33]$. The cosmetic advantage is stressed over and over again even with the knowledge that this is in unique for every patient. Regarding conventional multi-port laparoscopic surgery more than $90 \%$ of the patients are satisfied with the cosmetic results, therefore leaving only marginal room for improvements [34, 35].

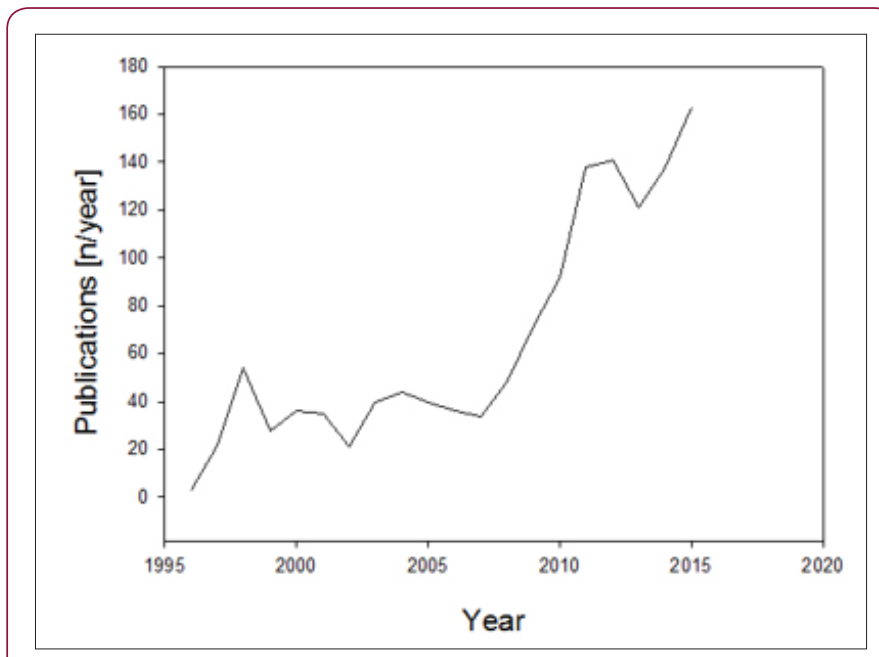

Figure 1: Number of publications per year in PubMed during the least 20 years period regarding single port/ incision surgery.

Long term data addressing the cosmetic perception after SILS are rare [36]. Furthermore, the term "scarless surgery" should be avoided since every access to the human body causes in scar - the only difference is the effort required for searching the scar. Apart 
from assessing the patient the surgeon shall not be forgotten since there are serious investigations showing that single port surgery increases the stress level within the team [37]. However, the SILS technique could further advance with the development of ergonomically improved instruments for laparoscopic surgery in general $[38,39]$. Further surgical spreading of the SILS procedures will be difficult to limit. Nevertheless, the basic question which patients take advantage of the procedure should be clarified; if this cannot achieved through RCT, at least data of all patients undergoing single port surgery should be captured in data bases to satisfy the scientific requirements. It remains the hope that ongoing trials to the various organ systems achieve a gain in knowledge $[9,40,41]$.

\section{References}

1 Chen K, Cao G, Chen B, Wang M, Xu X, et al. (2017) Laparoscopic versus open surgery for rectal cancer: A meta-analysis of classic randomized controlled trials and high-quality Nonrandomized Studies in the last 5 years. International journal of surgery 39: 1-10.

2 Kapischke M, Friedrich F, Hedderich J, Schulz T, Caliebe A (2011) Laparoscopic versus open appendectomy--quality of life 7 years after surgery. Langenbeck's archives of surgery 396(1): 69-75.

3 Raue W, Paolucci V, Asperger W, Albrecht R, Buchler MW (2011) Laparoscopic sigmoid resection for diverticular disease has no advantages over open approach: midterm results of a randomized controlled trial. Langenbeck's archives of surgery 396(7): 973-980.

4 Schwenk W (2004) The LAPDIV-CAMIC Study. Multicenter prospective randomized study of short-term and intermediate-term outcome of laparoscopic and conventional sigmoid resection in diverticular disease. Der Chirurg; Zeitschrift fur alle Gebiete der operativen Medizen 75(7): 706-707.

5 Kumar CVP (2011) Different Types of Single Incision Laparoscopy Surgery (SILS) Ports. World J Laparosc Surg 4(1): 47-51.

6 Pelosi MA, Pelosi MA (1992) Laparoscopic appendectomy using a single umbilical puncture (minilaparoscopy). The Journal of reproductive medicine 37(7): 588-594.

7 Navarra G, Pozza E, Occhionorelli S, Carcoforo P, Donini I (1997) Onewound laparoscopic cholecystectomy. The British journal of surgery 84(5): 695

8 Piskun G, Rajpal S (1999) Transumbilical laparoscopic cholecystectomy utilizes no incisions outside the umbilicus. Journal of laparoendoscopic \& advanced surgical techniques Part A 9(4): 361-364.

9 Brockhaus AC, Sauerland S, Saad S (2016) Single-incision versus standard multi-incision laparoscopic colectomy in patients with malignant or benign colonic disease: a systematic review, meta-analysis and assessment of the evidence. BMC surgery 16(1): 71.

10 Garg P, Thakur JD, Singh I, Nain N, Mittal G, et al. (2012) A prospective controlled trial comparing single-incision and conventional laparoscopic cholecystectomy: caution before damage control. Surgical laparoscopy, endoscopy \& percutaneous techniques 22(3): 220-225.

11 Marks JM, Phillips MS, Tacchino R, Roberts K, Onders R (2013) Singleincision laparoscopic cholecystectomy is associated with improved cosmesis scoring at the cost of significantly higher hernia rates: 1-year results of a prospective randomized, multicenter, single-blinded trial of traditional multiport laparoscopic cholecystectomy vs single-incision laparoscopic cholecystectomy. Journal of the American College of Surgeons 216(6): 1037-1047.

12 Antoniou SA, Morales-Conde S, Antoniou GA, Granderath FA, Berrevoet F, et al. (2016) Single-incision laparoscopic surgery through the umbilicus is associated with a higher incidence of trocar-site hernia than conventional laparoscopy: a meta-analysis of randomized controlled trials. Hernia: the journal of hernias and abdominal wall surgery $20(1)$ : $1-10$.
13 Vestweber B, Vestweber KH, Paul C, Rink AD (2016) Single-port laparoscopic resection for diverticular disease: experiences with more than 300 consecutive patients. Surg Endosc 30(1): 50-58.

14 Pisanu A, Reccia I, Porceddu G, Uccheddu A (2012) Meta-analysis of Prospective Randomized Studies Comparing Single-Incision Laparoscopic Cholecystectomy (SILC) and Conventional Multiport Laparoscopic Cholecystectomy (CMLC). Journal of Gastrointestinal Surgery 16(9): 1790-1801.

15 Christensen AM (2013) Commentary on "meta-analysis of prospective randomized studies comparing single-incision laparoscopic cholecystectomy (SILC) and conventional multiport laparoscopic cholecystectomy (CMLC)." In: Pisanu A, Reccia I, Porceddu G, et al. (Eds.) (J Gastrointest Surg 2012; 16:1790-1801) Journal of gastrointestinal surgery: official journal of the Society for Surgery of the Alimentary Tract 17(11): 2028.

16 Hall TC, Dennison AR, Bilku DK, Metcalfe MS, Garcea G (2012) Singleincision laparoscopic cholecystectomy: a systematic review. Archives of surgery 147(7): 657-666.

17 Allemann P, Schafer M, Demartines N (2010) Critical appraisal of single port access cholecystectomy. The British journal of surgery 97(10): 1476-1480.

18 Hajong R, Hajong D, Natung T, Anand M, Sharma G (2016) A Comparative Study of Single Incision versus Conventional Four Ports Laparoscopic Cholecystectomy. Journal of clinical and diagnostic research: JCDR 10(10): PC06-PC09.

19 Wu S, Lai H, Zhao J, Deng X, Wei J, (2016) Systematic review and metaanalysis of single-incision versus conventional multiport laparoscopic splenectomy. J Minim Access Surg 14(1): 1-8.

20 Lirici MM, Tierno SM, Ponzano C (2016) Single-incision laparoscopic cholecystectomy: does it work? A systematic review. Surgical Endoscopy 30(10): 4389-4399.

21 Guo W, Liu Y, Han W, Liu J, Jin L (2015) Randomized Trial of Immediate Postoperative Pain Following Single-incision Versus Traditional Laparoscopic Cholecystectomy. Chinese medical journal 128(24): 33103316.

22 Carter JT, Kaplan JA, Nguyen JN, Lin MY, Rogers SJ (2014) A prospective, randomized controlled trial of single-incision laparoscopic vs conventional 3-port laparoscopic appendectomy for treatment of acute appendicitis. Journal of the American College of Surgeons 218(5): 950959.

23 Gurusamy KS, Vaughan J, Rossi M, Davidson BR (2014) Fewer-than-four ports versus four ports for laparoscopic cholecystectomy. The Cochrane database of systematic reviews 20(2): CD007109.

24 Sulu B, Yildiz BD, Ilingi ED, Gunerhan Y, Cakmur H, et al. (2015) Single Port vs. Four Port Cholecystectomy-Randomized Trial on Quality of Life. Advances in clinical and experimental medicine: official organ Wroclaw Medical University 24(3): 469-473.

25 Zapf M, Yetasook A, Leung D, Salabat R, Denham W, et al. (2013) Singleincision results in similar pain and quality of life scores compared with multi-incision laparoscopic cholecystectomy: A blinded prospective randomized trial of 100 patients. Surgery 154(4): 662-670.

26 Zehetner J, Pelipad D, Darehzereshki A, Mason RJ, Lipham JC, et al. (2013) Single-access laparoscopic cholecystectomy versus classic laparoscopic cholecystectomy: a systematic review and meta-analysis of randomized controlled trials. Surgical laparoscopy, endoscopy \& percutaneous techniques 23(3): 235-243.

27 Lee WS, Choi ST, Lee JN, Kim KK, Park YH, et al. (2013) Single-port laparoscopic appendectomy versus conventional laparoscopic appendectomy: a prospective randomized controlled study. Annals of surgery 257(2): 214-218.

28 Islam S, Adams SD, Mahomed AA (2012) SILS: Is It Cost- and TimeEffective Compared to Standard Pediatric Laparoscopic Surgery? Minimally Invasive Surgery. 
29 Ko YS, Yoon SY, Han HJ, Yim TW, Song TJ (2015) A new glove port for single incision procedure. Annals of surgical treatment and research 89(5): 284-286.

30 Papaconstantinou HT, Sharp N, Thomas JS (2011) Single-Incision Laparoscopic Right Colectomy: A Case-Matched Comparison with Standard Laparoscopic and Hand-Assisted Laparoscopic Techniques. Journal of the American College of Surgeons 213(1): 72-80.

31 Valero-Navarro G, Pellicer-Franco E, Soria-Aledo V, Mengual-Ballester M, Garcia-Marin JA, et al. (2014) Single-port transanal endoscopic microsurgery: a developing technique. Surgical laparoscopy, endoscopy \& percutaneous techniques 24(4): 143-145.

32 Rimonda R, Arezzo A, Arolfo S, Salvai A, Morino M (2013) TransAnal Minimally Invasive Surgery (TAMIS) with SILS ${ }^{\mathrm{TM}}$ Port versus Transanal Endoscopic Microsurgery (TEM): a comparative experimental study. Surgical Endoscopy 27(10): 3762-3768.

33 Khorgami Z, Shoar S, Shoar N, Shakoor D, Mahdavian S, et al. (2014) Single Incision Laparoscopic Surgery: Review of Pros and Cons. Academic Journal of Surgery 1(1-2): 25-32.

34 Monkhouse SJW, Court EL, Beard LA, Bunni J, Burgess P (2012) A retrospective wound review of standard four-port laparoscopic cholecystectomy: Is there need for single-port laparoscopic surgery? Surgical Endoscopy 26(1): 255-260.

35 Bignell M, Hindmarsh A, Nageswaran H, Mothe B, Jenkinson A, et al. (2011) Assessment of cosmetic outcome after laparoscopic cholecystectomy among women 4 years after laparoscopic cholecystectomy: is there a problem? Surg Endosc 25(8): 2574-2577.

\section{ISSN: 2574-1241}

DOI: $10.26717 /$ BJSTR.2018.07.001447

Matthias Kapischke. Biomed J Sci \& Tech Res

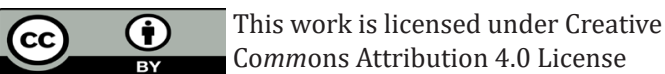

Submission Link: https://biomedres.us/submit-manuscript.php
36 Lurje G, Raptis DA, Steinemann DC, Amygdalos I, Kambakamba P, et al. (2015) Cosmesis and Body Image in Patients Undergoing Single-port Versus Conventional Laparoscopic Cholecystectomy: A Multicenter Double-blinded Randomized Controlled Trial (SPOCC-trial). Annals of surgery 262(5): 728-734.

37 Abdelrahman AM, Bingener J, Yu D, Lowndes BR, Mohamed A, et al. (2016) Impact of single-incision laparoscopic cholecystectomy (SILC) versus conventional laparoscopic cholecystectomy (CLC) procedures on surgeon stress and workload: a randomized controlled trial. Surg Endosc 30(3): 1205-1211.

38 Herring SR, Trejo AE, Hallbeck MS (2010) Evaluation of four cursor control devices during a target acquisition task for laparoscopic tool control. Applied ergonomics 41(1): 47-57.

39 Trejo A, Jung MC, Oleynikov D, Hallbeck MS (2007) Effect of handle design and target location on insertion and aim with a laparoscopic surgical tool. Applied ergonomics 38(6): 745-753.

40 Malik M, McCormack K, Krukowski ZH, McDonald A, McPherson G, et al. (2012) Single port/incision laparoscopic surgery compared with standard three-port laparoscopic surgery for appendicectomy - a randomised controlled trial. Trials 13: 201.

41 Wang Y, Liu R, Zhang Z, Xue Q, Yan J, et al. (2015) A safety study of transumbilical single incision versus conventional laparoscopic surgery for colorectal cancer: study protocol for a randomized controlled trial. Trials 16: 539.

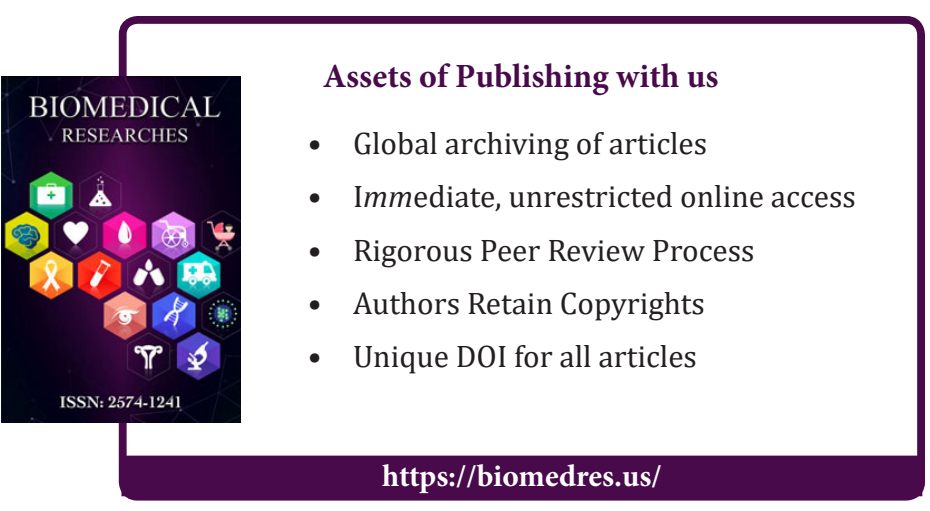

